\title{
Optic Nerve Topography in Multiple Sclerosis Diagnosis
}

\author{
The Utility of Visual Evoked Potentials
}

Angela Vidal-Jordana, MD, PhD, Alex Rovira, MD, Georgina Arrambide, MD, PhD, Susana Otero-Romero, MD, PhD, Jordi Río, MD, PhD, Manuel Comabella, MD, PhD, Carlos Nos, MD, Joaquin Castilló, MD, PhD, Ingrid Galan, MD, Sergio Cabello, Dulce Moncho, MD, Kimia Rahnama, MD, Vanessa Thonon, MD, Breogan Rodríguez-Acevedo, MD, Ana Zabalza, MD, Luciana Midaglia, MD, Cristina Auger, MD, Jaume Sastre-Garriga, MD, PhD, Xavier Montalban, MD, PhD, * and Mar Tintoré, MD, PhD* Neurology ${ }^{\circledR}$ 2021;96:e482-e490. doi:10.1212/WNL.0000000000011339

\section{Abstract}

\section{Objective}

To assess the added value of the optic nerve region (by using visual evoked potentials [VEPs]) to the current diagnostic criteria.

\section{Methods}

From the Barcelona clinically isolated syndrome (CIS) cohort, patients with complete information to assess dissemination in space (DIS), the optic nerve region, and dissemination in time at baseline $(\mathrm{n}=388)$ were selected. Modified DIS (modDIS) criteria were constructed by adding the optic nerve to the current DIS regions. The DIS and modDIS criteria were evaluated with univariable Cox proportional hazard regression analyses with the time to the second attack as the outcome. A subset of these patients who had at least 10 years of follow-up or a second attack occurring within 10 years $(\mathrm{n}=151)$ were selected to assess the diagnostic performance. The analyses were also performed according to CIS topography (optic neuritis vs non-optic neuritis).

\section{Results}

The addition of the optic nerve as a fifth region improved the diagnostic performance by slightly increasing the accuracy (2017 DIS 75.5\%, modDIS 78.1\%) and the sensitivity (2017 DIS 79.2\%, modDIS $82.3 \%$ ) without lowering the specificity (2017 DIS 52.4\%, modDIS 52.4\%). When the analysis was conducted according to CIS topography, the modDIS criteria performed similarly in both optic neuritis and non-optic neuritis CIS.

\section{Conclusion}

The addition of the optic nerve, assessed by VEP, as a fifth region in the current DIS criteria slightly improves the diagnostic performance because it increases sensitivity without losing specificity.

\author{
Correspondence \\ Dr. Vidal-Jordana \\ avidal@cem-cat.org
}

\section{RELATED ARTICLE}

\section{Editorial}

Optic Nerve in Multiple

Sclerosis Diagnostic

Criteria: An Aye to the

Eyes?

Page 139

\footnotetext{
*These authors contributed equally to this work.

From the Servicio de Neurología-Neuroinmunología (A V.-J., G.A., S.O.-R., J.R., M.C., C.N., J.C., I.G., S.C., B.R.-A., A.Z., L.M., J.S.-G., X.M., M.T.), Centro de Esclerosis Múltiple de Catalunya (Cemcat), Sección de Neuroradiologia (A.R., C.A.), Servei de Radiologia, Servicio de Medicina Preventiva y Epidemiologia (S.O.-R.), and Servicio de Neurofisiología Clínica (D.M., K.R. V.T.), Hospital Universitari Vall d'Hebron, Universitat Autònoma de Barcelona, Spain; and Division of Neurology (X.M.), St. Michael's Hospital. University of Toronto, Ontario, Canada.

Go to Neurology.org/N for full disclosures. Funding information and disclosures deemed relevant by the authors, if any, are provided at the end of the article.

The Article Processing Charge was funded by Fondo de Investigación en Salud (FIS: PI17/02162) from Instituto de Salud Carlos III, Ministry of Science, Innovation and Universities, Spain.

This is an open access article distributed under the terms of the Creative Commons Attribution-NonCommercial-NoDerivatives License 4.0 (CC BY-NC-ND), which permits downloading and sharing the work provided it is properly cited. The work cannot be changed in any way or used commercially without permission from the journal.
} 


\section{Glossary}

$\mathbf{C I}=$ confidence interval; $\mathbf{C I S}=$ clinically isolated syndrome; $\mathbf{D I S}=$ dissemination in space; $\mathbf{D I T}=$ dissemination in time; $\mathbf{H R}=$ hazard ratio; MAGNIMS = Magnetic Resonance Imaging in Multiple Sclerosis; modDIS = modified DIS; MS = multiple sclerosis; $\mathbf{O B}=$ oligoclonal bands; $\mathbf{O C T}$ = optical coherence tomography; VEP = visual evoked potential.

The improvement in diagnosis is one of the main advances that have occurred in the multiple sclerosis (MS) field in the past decades. Since 2001, ${ }^{1}$ dissemination in space (DIS) and in time (DIT) can be established from MRI findings, and since 2010, the diagnosis can be stablished shortly after presenting a typical clinically isolated syndrome (CIS) on the results of a single baseline MRI. ${ }^{2,3}$ More recently, oligoclonal bands (OB) have been reincorporated into the 2017 diagnostic criteria as an alternative criterion for diagnosing MS in the absence of DIT. ${ }^{3,4}$

Optic neuritis represents the first manifestation of MS in $25 \%$ to $35 \%$ of patients with CIS $^{5,6}$ and will occur during disease course in $\approx 70 \%$ of patients. ${ }^{5}$ The involvement of the optic nerve can be established either clinically or by the use of paraclinical tests such as visual evoked potentials (VEPs), MRI, and optical coherence tomography (OCT). In 2016, the Magnetic Resonance Imaging in Multiple Sclerosis (MAGNIMS) group proposed the inclusion of the optic nerve as an additional region to demonstrate DIS. ${ }^{7}$ However, due to the lack of evidence regarding the diagnostic properties of the different tests to assess the optic nerve involvement in patients with CIS, the optic nerve was finally not incorporated into the most recent revision of the McDonald diagnostic criteria. ${ }^{3}$

A few studies have investigated the anterior visual pathway involvement in CIS cohorts using clinical features, ${ }^{8}$ $\mathrm{VEP},{ }^{8,9} \mathrm{OCT},{ }^{10-13}$ and $\mathrm{MRI}^{9,12,14}$ alone or in combination, but only 2 of them have evaluated the diagnostic performance of adding the optic nerve as a new region in the diagnostic criteria, ${ }^{8,9}$ yielding somewhat contradictory results. While the first study ${ }^{8}$ found that the addition of optic nerve (evaluated mainly by clinical assessment) would improve the diagnostic performance of 2017 McDonald criteria only in patients with optic neuritis CIS, the study conducted by the MAGNIMS group ${ }^{9}$ concluded that there was no clear improvement of the $2010 \mathrm{McDo}$ nald criteria when the optic nerve region (assessed mainly by VEP) was added to the 2010 DIS criteria. Moreover, the modified DIS criterion that included the optic nerve was the one with the lowest specificity. ${ }^{9}$

In this work, we have investigated the effect of adding the optic nerve region (evaluated by VEP) as part of the DIS criteria to improve the 2017 diagnostic criteria in a well-characterized cohort of patients with CIS. ${ }^{6}$ We have also compared the added value of the fifth region according to optic nerve involvement (symptomatic vs asymptomatic CIS).

\section{Methods}

\section{Study Cohort}

This observational, retrospective study was based on the Barcelona CIS cohort. Clinical, demographic, biological, and radiologic data are collected prospectively following a prespecified protocol described elsewhere. ${ }^{6,15}$ Briefly, patients $<50$ years of age first seen within 3 months of symptom onset were included. Demographic data, CIS topography, and presence of $\mathrm{OB}$ at baseline were recorded, together with the occurrence of a second attack during follow-up. Brain MRI was obtained at baseline (within 5 months after CIS onset), at 1 year, and every 5 years thereafter. Beginning in 2007, spinal cord MRIs were done at baseline as part of the diagnostic process in all patients with CIS. MRI scans were obtained at 3.0T since 2010 and at $1.5 \mathrm{~T}$ previously. Each MRI scan was assessed by experienced neuroradiologists under normal reporting conditions.

Pattern-reversal VEPs were performed during the diagnostic process in the same location by an expert neurophysiologist from the Neurophysiology Unit following international guidelines. ${ }^{16}$ Although this is a prospective CIS cohort, the date of VEP was not part of the initially collected information. However, we have been able to retrieve this information from electronic clinical records for 288 patients (74.2\%). VEPs were performed with a mean time from CIS to VEP of 3.95 months (SD 3.82 months). Preexisting eye conditions were taken into account when VEP results were interpreted. Patients presenting with any ocular pathology that may affect VEP were excluded. According to our normative data, VEPs were considered abnormal if the latency of the P100 wave was $>112$ milliseconds, there was an intereye latency asymmetry $>8$, milliseconds, or there was an absence of the P100 wave.

\section{Study Design}

To evaluate the effect of adding new regions to fulfill DIS, we performed a risk assessment analysis. We selected patients with complete information to assess the 5 DIS regions (brain and spinal cord MRI plus VEPs) and with gadolinium administration at baseline to assess DIT (cohort 1). From this cohort and to ensure that late converters were taken into account, patients who had at least 10 years of follow-up or who experienced a second attack within 10 years of the CIS were selected to test the diagnostic criteria performance (cohort 2) (figure). For both cohorts, DIS and DIT were assessed at baseline. The modified DIS (modDIS) criteria were constructed by adding the optic nerve region to the current DIS topographies and using a cutoff value of 2 of 5 . The second attack was determined when new symptoms 
suggestive of a relapse occurred during the follow-up after an interval of at least 1 month since the CIS and in the absence of fever or concurrent diseases. ${ }^{17}$

\section{Statistical Analysis}

Descriptive statistics were performed on the baseline variables. Normally distributed continuous variables were summarized with means and SDs. Otherwise, continuous variables were summarized with medians and ranges; categorical variables were summarized as percentages.

\section{Cohort 1, Risk Assessment Analysis}

For the risk assessment analysis, the number of DIS regions fulfilled and the current and modDIS criteria were evaluated with univariable Cox proportional hazard regression analyses considering the time to the second attack during the follow-up as the primary outcome and the time to $2017 \mathrm{McD}$ onald MS criteria fulfillment as the secondary outcome. The results are expressed as the hazard ratios (HRs) with 95\% confidence intervals (CIs). The Schoenfeld residuals have been evaluated to test the proportional risk assumption. Finally, because initiating a disease-modifying treatment before a second attack could have affected the primary outcome, a sensitivity analysis with treatment exposure as a time-dependent variable was also conducted.

\section{Cohort 2, Diagnostic Criteria Performance}

We analyzed the sensitivity, specificity, accuracy, positive predictive value, and negative predictive value of the current and modDIS criteria alone and in combination with either $\mathrm{OB}$ or MRI DIT, with second attack and 2017 McDonald MS at 10 years as the primary and secondary outcomes, respectively. A sensitivity analysis excluding patients with treatment onset before presenting a second attack was conducted.

To test whether the fulfillment of the modDIS criteria would have a different impact in symptomatic (optic neuritis) and asymptomatic (non-optic neuritis) patients with CIS, both risk assessment and diagnostic performance analyses were conducted according to CIS topography.

All statistical tests were performed with SPSS software version 22 (SPSS Inc, Chicago, IL) and R version 3.6.0 (R Foundation for Statistical Computing, Vienna, Austria).

\section{Standard Protocol Approvals and Patient Consents}

This study received approval from the Clinical Research Ethics Committee at Vall d'Hebron University Hospital. All patients signed written informed consents. 


\section{Data Availability}

Anonymized data will be shared by request from any qualified investigator.

\section{Results}

From January 1995 to December 2017, 1,337 patients were included in the Barcelona CIS inception cohort; 99 patients were excluded for different reasons (figure). Of the remaining 1,238 patients, 388 fulfilled the criteria for the risk assessment analysis (cohort 1), and 151 were included in the diagnostic criteria performance analysis (cohort 2). Baseline characteristics of the whole cohort, cohort 1 , and cohort 2 are detailed in table 1 . Of note, in the whole cohort $(n=1,238)$, patients were younger, and there was a higher proportion of patients with positive $\mathrm{OB}$ and with abnormal VEPs.

VEPs were abnormal in 126 of 388 patients (32.5\%), being asymptomatic in $13.6 \%$. Mean time of follow-up was 62.7 months (SD 40.4 months) for cohort 1 and 88.9 months (SD 37.9 months) for cohort 2. Patients with the longest follow-up (cohort 2) had a greater proportion of abnormal baseline MRI and positive OB results. One hundred thirty patients (33.5\%) presented a second attack, and all occurred within the first 10 years after CIS onset (mean time 19.6 months, SD 22.3 months).

\section{Risk Assessment Analysis (Cohort 1)}

After presentation of a CIS, the risk of developing a second attack during the follow-up increased as the number of regions fulfilled at baseline increased (from HR 5.6, 95\% CI 1.9-16.5 for 1 criterion to HR 22.7, 95\% CI 7.9-65.7 for 5 criteria affected) (table 2).

Both the 2017 DIS and modDIS criteria at baseline conferred a similar risk for developing a second attack during follow-up compared to patients not fulfilling these criteria (2017 DIS: HR 4.3, 95\% CI 2.8-6.5; modDIS: HR 4.8, 95\% CI 3.0-7.5) (table 2). Similar findings were obtained with the $2017 \mathrm{McDonald} M S$ as the outcome although with wider CIs (2017 DIS: HR 20.4, 95\% CI 13.6-30.6; modDIS: HR 21.8, 95\% CI 14.1-33.9).

In the sensitivity analysis including treatment exposure as a timedependent variable, similar results were found (HR 4.6, 95\% CI 2.9-7.2 for 2017 DIS; HR 5.1, 95\% CI 3.1-8.3 for modDIS).

When the risk assessment analysis was conducted according to CIS topography, fulfilling either the 2017 DIS or modDIS criteria (including the optic nerve region) conferred a similar higher risk for developing a second attack during the followup in patients with both optic neuritis and non-optic neuritis CIS (table 3).

\section{Diagnostic Criteria Performance Analysis (Cohort 2)}

The addition of the optic nerve region to the DIS criteria improved the current DIS diagnostic performance by increasing the accuracy and sensitivity without decreasing the specificity (table 4). When the current and modDIS criteria were considered along with the presence of OB or DIT, the modified criteria remained more accurate and more sensitive and had a specificity similar to that of the current 2017 McDonald MS criteria, although the improvement was less

Table 1 Baseline Characteristics

\begin{tabular}{|c|c|c|c|}
\hline & Whole Cohort $(n=1,238)$ & Cohort $1(n=388)$ & Cohort $2(n=151)$ \\
\hline Age at CIS, mean (SD), y & $31.6(8.2)$ & $33.5(7.8)$ & $32.4(7.4)$ \\
\hline Female, n (\%) & $842(68.0)$ & $263(67.8)$ & $108(71.5)$ \\
\hline \multicolumn{4}{|l|}{ CIS topography, n (\%) } \\
\hline Optic neuritis & $446(36.0)$ & $138(35.6)$ & $40(26.5)$ \\
\hline Non-optic neuritis & $787(63.6)$ & $250(64.4)$ & $111(73.5)$ \\
\hline Positive OB, n (\%) & $582 / 990(58.8)$ & $182 / 335(54.3)$ & $100 / 136(73.5)$ \\
\hline Baseline EDSS score, median (range) & $1.0(0-5.5)$ & $1.0(0-4.5)$ & $1.5(0-4.5)$ \\
\hline Abnormal MRI, n (\%) & $810(71.2)$ & $275(71.1)$ & $136(90.1)$ \\
\hline Gd-enhancing lesions, n (\%) & $235(29.3)$ & $114(29.4)$ & $71(47.0)$ \\
\hline Patients with abnormal VEPs, n (\%) & $415 / 1,098(37.8)$ & $126(32.5)$ & $53(35.1)$ \\
\hline Optic neuritis & $297 / 416(71.4)$ & $92 / 138(66.7)$ & $28 / 40(70.0)$ \\
\hline Non-optic neuritis & $118 / 682(17.3)$ & $34 / 250(13.6)$ & $25 / 111(22.5)$ \\
\hline Time of follow-up, mean (SD), mo & $107.9(98.0)$ & $62.7(40.4)$ & $88.9(37.9)$ \\
\hline
\end{tabular}

Abbreviations: CIS = clinically isolated syndrome; EDSS = Expanded Disability Status Scale; OB = oligoclonal bands; VEP = visual evoked potential. 
Table 2 Risk Assessment Analysis for the Whole Cohort: HRs for Second Attack as the Outcome

\begin{tabular}{llll}
\hline & No. (\%) & Second Attack, $\mathbf{~ ( \% )}$ & HR (95\% CI) \\
\hline No. of regions affected & & & \\
\hline $\mathbf{1}$ criterion & $78(20.1)$ & $19 / 78(24.4)$ & $5.6(1.9-16.5)$ \\
\hline $\mathbf{2}$ criteria & $49(12.6)$ & $21 / 49(42.9)$ & $11.7(4.0-34.2)$ \\
\hline $\mathbf{3}$ criteria & $71(18.3)$ & $38 / 71(53.5)$ & $15.8(5.6-44.4)$ \\
\hline $\mathbf{4}$ criteria & $57(14.7)$ & $24 / 57(42.1)$ & $12.5(4.3-36.1)$ \\
\hline $\mathbf{5}$ criteria & $39(10.1)$ & $24 / 39(61.5)$ & $22.7(7.9-65.7)$ \\
\hline $\mathbf{2 0 1 7}$ DIS vs modDIS & & & $4.3(2.8-6.5)$ \\
\hline $\mathbf{2 0 1 7}$ DIS & $205(52.8)$ & $103 / 205(50.2)$ & $4.8(3.0-7.5)$ \\
\hline modDIS & $216(55.7)$ & $107 / 216(49.5)$ & \\
\hline
\end{tabular}

Abbreviations: $\mathrm{Cl}$ = confidence interval; $\mathrm{DIS}=$ dissemination in space; $\mathrm{HR}=$ hazard ratio; modDIS = modified DIS

The 2017 DIS criteria as defined in Thompson et al. ${ }^{3}$ : at least 1 lesion in at least 2 of 4 areas of the CNS (periventricular, cortico-juxtacortical, infratentorial, spinal cord). modDIS added optic nerve assessed by visual evoked potential: at least 1 lesion in at least 2 of 5 areas of the CNS (periventricular, corticojuxtacortical, infratentorial, spinal cord, optic nerve).

noticeable than when DIS was analyzed alone (table 4). Similar results were obtained with $2017 \mathrm{McDonald}$ MS as the outcome (2017 DIS vs modDIS: sensitivity $80.7 \%$ vs $83.6 \%$, specificity $100 \%$ vs $100 \%$, accuracy $82.1 \%$ vs $84.8 \%$ ) and in the sensitivity analysis including only patients who either were never treated or started treatment after presenting a second attack (data not shown).

When the diagnostic performance analysis was conducted according to CIS topography, the addition of the optic nerve region improved the current DIS diagnostic performance in patients with both optic neuritis vs non-optic neuritis CIS, although this improvement was more noticeable in symptomatic (optic neuritis) patients (table 5). Again, when the different DIS criteria were considered in combination with presence of $\mathrm{OB}$ or DIT, adding the optic nerve region into the DIS criteria also resulted in more accurate, more sensitive diagnostic criteria, with a specificity similar to that of the 2017
McDonald MS criteria, although this improvement was less noticeable (table 5).

\section{Discussion}

In patients presenting a CIS, the addition of the optic nerve (both in symptomatic and asymptomatic patients) as a fifth region to the current DIS criteria confers a higher risk for developing a second attack during follow-up and slightly improves the diagnostic criteria performance by increasing sensitivity without losing specificity.

In our work, we have demonstrated that patients fulfilling the modDIS criteria at baseline were at a high risk of developing a second attack during follow-up, which was similar to the risk observed in patients fulfilling the 2017 DIS criteria. These findings are in line with the work by Filippi et al. ${ }^{9}$ that

Table 3 Risk Assessment Analysis According to Optic Nerve Involvement: HRs for Second Attack as the Outcome

\begin{tabular}{|c|c|c|c|}
\hline & No. (\%) & Second Attack n (\%) & $\mathrm{HR}(95 \% \mathrm{Cl})$ \\
\hline \multicolumn{4}{|c|}{ Optic neuritis CIS ( $n=138$ ) } \\
\hline 2017 DIS & $61(44.2)$ & 23/61 (37.7) & $3.8(1.8-8.0)$ \\
\hline modDIS & $70(50.7)$ & $25 / 70(35.7)$ & $4.3(1.9-9.6)$ \\
\hline \multicolumn{4}{|c|}{ Non-optic neuritis CIS $(n=250)$} \\
\hline 2017 DIS & $144(57.6)$ & $80 / 144(55.6)$ & $4.1(2.4-6.9)$ \\
\hline modDIS & $146(58.4)$ & $82 / 146(56.2)$ & $4.6(2.7-8.0)$ \\
\hline
\end{tabular}

Abbreviations: $\mathrm{Cl}$ = confidence interval; $\mathrm{CIS}=$ clinically isolated syndrome; $\mathrm{DIS}=$ dissemination in space; $\mathrm{HR}$ = hazard ratio; modDIS = modified DIS. The 2017 DIS criteria as defined in Thompson et al. ${ }^{3}$ : at least 1 lesion in at least 2 of 4 areas of the CNS (periventricular, cortico-juxtacortical, infratentorial, spinal cord). modDIS added optic nerve assessed by visual evoked potential: at least 1 lesion in at least 2 of 5 areas of the CNS (periventricular, corticojuxtacortical, infratentorial, spinal cord, optic nerve). 
Table 4 Diagnostic Performance Analysis: Diagnostic Properties at 10 years With Second Attack as the Outcome

\begin{tabular}{llllll}
\hline & $\%(95 \% \mathrm{Cl})$ & & & \\
\cline { 2 - 6 } & Sensitivity & Specificity & Accuracy & PPV & NPV \\
\hline 2017 DIS & $79.2(71.2-85.8)$ & $52.4(29.8-74.3)$ & $75.5(67.8-82.1)$ & $91.1(86.7-94.2)$ & $28.9(19.4-40.9)$ \\
\hline modDIS & $82.3(74.6-88.4)$ & $52.4(29.8-74.3)$ & $78.1(70.7-84.5)$ & $91.4(87.1-94.4)$ & $32.3(21.6-45.4)$ \\
\hline 2017 DIS + DIT and/or OB & $73.9(65.4-81.2)$ & $66.7(43.0-85.4)$ & $72.9(62.0-79.8)$ & $93.2(88.1-96.2)$ & $29.2(21.3-38.5)$ \\
\hline modDIS + DIT and/or OB & $74.2(65.9-81.5)$ & $66.7(43.0-85.4)$ & $73.2(65.5-80.0)$ & $93.2(88.4-96.3)$ & $29.2(21.3-38.5)$ \\
\hline
\end{tabular}

Abbreviations: $\mathrm{Cl}$ = confidence interval; $\mathrm{DIS}=$ dissemination in space; $\mathrm{DIT}=$ dissemination in time; modDIS = modified DIS; NPV = negative predictive value; OB = oligoclonal bands; PPV = positive predictive value.

The 2017 DIS criteria as defined in Thompson et al. ${ }^{3}$ : at least 1 lesion in at least 2 of 4 areas of the CNS (periventricular, cortico-juxtacortical, infratentorial, spinal cord). modDIS added optic nerve assessed by visual evoked potential: at least 1 lesion in at least 2 of 5 areas of the CNS (periventricular, corticojuxtacortical, infratentorial, spinal cord, optic nerve).

evaluated the optic nerve involvement (mainly using VEPs) in 241 patients with CIS, reporting a similar higher risk for developing a second attack when patients fulfilled either the 2010 DIS criteria or the 2010 modDIS criteria including the optic nerve (2010 DIS: 3.48, 95\% CI 2.2-5.6; 2010 DIS plus optic nerve: 3.34, 95\% CI 1.9-5.6). In addition, we have conducted the risk assessment analysis based on CIS topography to test whether the fulfillment of the modDIS criteria would have a different impact in symptomatic and asymptomatic patients with CIS (optic neuritis vs non-optic neuritis CIS) and found similar results. This probably means that VEPs were able to capture optic nerve involvement in both symptomatic and asymptomatic eyes ${ }^{18}$ and reinforces the fact that symptomatic lesions should be taken into account when considering the diagnosis of MS in patients with CIS. ${ }^{19,20}$
As for the diagnostic performance analysis, we have proved that the addition of the optic nerve to the current DIS criteria slightly increases the accuracy and sensitivity without lowering the specificity, both in the whole cohort and in symptomatic and asymptomatic patients with CIS. These results are partially discordant with the results published in 2 previous works showing that the addition of the optic nerve to the DIS criteria increased the sensitivity at the expense of decreasing the specificity. ${ }^{8,9}$ In the first work, Filippi et al. ${ }^{9}$ found that the addition of the optic nerve region to the 2010 DIS criteria increased the sensitivity by lowering the specificity of the 2010 criteria with second attack 5 years after presenting the CIS used as the outcome (sensitivity: 2010 DIS 0.87 vs 2010 DIS + optic nerve 0.90; specificity: 2010 DIS 0.33 vs 2010 DIS + optic nerve 0.26$).{ }^{9}$ More recently,

Table 5 Diagnostic Performance Analysis According to Optic Nerve Involvement: Diagnostic Properties at 10 years With Second Attack as the Outcome

\begin{tabular}{|c|c|c|c|c|c|}
\hline & \multicolumn{5}{|l|}{$\%(95 \% \mathrm{Cl})$} \\
\hline & Sensitivity & Specificity & Accuracy & PPV & NPV \\
\hline \multicolumn{6}{|l|}{ Optic neuritis CIS ( $n=40)$} \\
\hline 2017 DIS & $69.7(51.3-84.4)$ & $57.1(18.4-90.1)$ & $67.5(51.0-81.4)$ & $88.5(76.0-94.9)$ & $28.6(14.9-47.7)$ \\
\hline modDIS & $75.8(57.7-89.0)$ & $57.1(18.4-90.1)$ & $72.5(56.1-85.4)$ & $89.3(77.6-95.2)$ & $33.3(17.2-54.7)$ \\
\hline 2017 DIS + DIT and/or OB & $63.6(45.1-79.6)$ & $85.7(42.1-99.6)$ & $67.5(50.9-81.4)$ & $95.5(77.1-99.2)$ & $33.3(22.5-46.3)$ \\
\hline $\operatorname{modDIS}+\mathrm{DIT}$ and/or OB & $66.7(48.2-82.0)$ & $85.7(42.1-99.6)$ & $70.0(53.5-83.4)$ & $95.7(77.9-99.3)$ & $35.3(23.6-49.1)$ \\
\hline \multicolumn{6}{|c|}{ Non-optic neuritis CIS $(n=111)$} \\
\hline 2017 DIS & $82.5(73.4-89.5)$ & $50.0(23.0-77.0)$ & $78.4(69.6-85.6)$ & $91.9(87.0-95.1)$ & $29.2(17.3-44.8)$ \\
\hline modDIS & $84.5(75.8-91.1)$ & $50.0(23.0-77.0)$ & $80.2(71.5-87.1)$ & $92.1(87.3-95.2)$ & $31.8(18.8-48.5)$ \\
\hline 2017 DIS + DIT and/or OB & $77.3(67.7-85.2)$ & $57.1(28.9-82.3)$ & $74.8(65.7-82.5)$ & $92.6(87.1-95.9)$ & $26.7(16.9-39-5)$ \\
\hline $\operatorname{modDIS}+\mathrm{DIT}$ and/or OB & $78.4(68.8-86.1)$ & $57.1(28.9-82.3)$ & $75.7(66.6-83.3)$ & $92.7(87.3-95.9)$ & $27.6(17.4-40.8)$ \\
\hline
\end{tabular}

Abbreviations: $\mathrm{Cl}$ = confidence interval; CIS = clinically isolated syndrome; DIS = dissemination in space; DIT = dissemination in time; modDIS = modified DIS; $\mathrm{NPV}=$ negative predictive value; $\mathrm{OB}=$ oligoclonal bands; $\mathrm{PPV}=$ positive predictive value.

The 2017 DIS criteria as defined in Thompson et al. ${ }^{3}$ : at least 1 lesion in at least 2 of 4 areas of the CNS (periventricular, cortico-juxtacortical, infratentorial, spinal cord). modDIS added optic nerve assessed by visual evoked potential: at least 1 lesion in at least 2 of 5 areas of the CNS (periventricular, corticojuxtacortical, infratentorial, spinal cord, optic nerve). 
Brownlee et al. ${ }^{8}$ analyzed the diagnostic performance of the new modified criteria according to CIS topography (optic neuritis and non-optic neuritis CIS) using the presence of a second attack after a mean follow-up period of almost 15 years as the outcome. They reported that the inclusion of the symptomatic optic nerve involvement (assessed mainly clinically) increased the sensitivity and decreased the specificity of the 2017 DIS criteria (sensitivity: 2017 DIS $83 \%$ vs 2017 DIS + optic nerve 95\%; specificity: 2017 DIS 68\%, 2017 DIS + optic nerve 57\%). ${ }^{8}$ Both works reported that the decrease in specificity was no longer seen when the different DIS criteria were evaluated along with DIT criteria. The differences in the test specificity results between our work and the previous published works may be explained in part by the longer follow-up of our cohort compared with Filippi et al., which may have allowed us to detect late converters, or by the different methods used to evaluate optic nerve involvement in the Brownlee et al. work. Moreover, we have demonstrated that the addition of the optic nerve to the 2017 McDonald criteria increased the diagnostic performance in patients with both optic neuritis (symptomatic) and non-optic neuritis (asymptomatic) CIS, although to a greater extent in the former group. These results are partially discordant with the results published by Brownlee et al. and may be partly explained by a slight overrepresentation of optic neuritis in their work ${ }^{8}$ or by the fact that VEPs are more capable of detecting subclinical optic nerve involvement than clinical assessment alone. ${ }^{18,21-23}$

The 2016 MAGNIMS proposal suggested that optic nerve involvement may be ascertained clinically (by detecting optic nerve atrophy or pallor), with neurophysiologic tests (VEPs), or by imaging with either MRI to detect optic nerve lesions or OCT to detect peripapillary retinal nerve fiber layer thinning. ${ }^{7}$ Assessment of optic nerve involvement based only on clinical findings may be challenging if not assessed by a trained neuro-ophthalmologist, ${ }^{24}$ and thus, the use of paraclinical tests to confirm optic nerve damage may be advisable. In addition, if we are trying to increase the sensitivity of a diagnostic test, we may want to use paraclinical tests that may allow us to detect a higher proportion of patients with asymptomatic optic nerve involvement compared to clinical tools alone. Full-field VEPs have classically been used to provide paraclinical evidence of demyelination to support the diagnosis of MS. ${ }^{17}$ Very few studies have assessed VEPs in purely CIS cohorts, ${ }^{25-29}$ reporting rates of abnormal VEP results that range from $15 \%$ to $49 \%$ and that are in line with the abnormal VEP rate of our study (32.5\%). As expected, we have found VEPs to be more frequently affected in patients with optic neuritis CIS (66.7\%), which is a result similar to that reported in the literature $(67.8 \%-87 \%) .{ }^{25,29}$ Most of the studies evaluating VEPs in CIS cohorts were published before the implementation of the McDonald criteria ${ }^{25-27}$ to compare the diagnostic properties of VEP and MRI to detect patients at risk of developing MS during follow-up, concluding that the MRI was the most sensitive tool. ${ }^{25-27}$ While the diagnosis of MS has evolved tremendously since the use of MRI, our work demonstrates the utility of VEPs (in combination with brain and spinal cord MRI) in MS diagnosis, supporting the reintroduction of this test in the diagnostic workup of patients with CIS. It is important to bear in mind that VEP results may be influenced by several factors concerning test acquisition such as patient cooperation, luminescence and contrast patterns, and stimuli presentation rate. ${ }^{30,31}$ To minimize these factors, VEPs should be acquired following international guidelines, ${ }^{16}$ and a normative dataset obtained from normal controls using local equipment is commonly used to define the range of normal variation.

Some limitations should be taken into consideration in the interpretation of our results. VEPs were obtained as part of the routine diagnostic process of patients with CIS, but information on the time elapsed since CIS to VEP was available for only three-quarters of the patients. Because patients included in this analysis were slightly different from the full Barcelona CIS cohort $(n=1,238)$, we cannot exclude some minor selection bias. However, differences in VEP abnormalities were small (37.8 vs 32.5 ), and our results were still significant even with a lower proportion of abnormal VEPs in both cohorts 1 and 2 . We also acknowledge that by selecting only patients with complete information to analyze the modDIS criteria (having brain and spinal cord MRI together with VEP information) and DIT criteria (administration of gadolinium at baseline MRI), we could have enriched our cohort. Last, we are aware that diseasemodifying treatment started before second attack could have interfered with our results; however, no differences were found in our sensitivity analysis when this information was taken into account.

Since 2010, the McDonald diagnostic criteria have allowed the diagnosis of MS immediately after presentation of a typical CIS, ${ }^{2,3}$ reducing patients' uncertainty and improving earlier treatment onset. However, with the exclusion of the optic nerve as one of the relevant DIS regions, this early diagnosis may not be applied to all patients equally because symptomatic spinal cord and brainstem syndromes are more meaningful in the diagnostic process than optic neuritis. ${ }^{32-34}$ Thus, in a patient presenting a brainstem CIS, the diagnosis of MS can be established by showing 1 periventricular lesion and 1 enhancing brainstem lesion in brain MRI, while it will not be the case if the same patient had presented an optic neuritis with an abnormal VEP result and a brain MRI showing the same enhancing periventricular lesion.

Our results show that the addition of the optic nerve, assessed by VEP, as a fifth region in the current DIS criteria improves the diagnostic performance by slightly increasing sensitivity without losing specificity. Thus, our work provides additional evidence that argues in favor of including the optic nerve as a new region in the diagnostic criteria. Whether the optic nerve involvement in patients with CIS should be confirmed only by 
means of VEPs, by the use of other structural tests (MRI or OCT), or by a combination of them requires further investigation in prospective studies with a systematic examination of the optic nerve in patients with CIS.

\section{Study Funding}

No targeted funding reported.

\section{Disclosures}

Angela Vidal-Jordana receives support for contracts Juan Rodes (JR16/00024) from Fondo de Investigaciones Sanitarias, Instituto de Salud Carlos III, Spain, and has engaged in consulting and/or participated as speaker in events organized by Novartis, Roche, Teva, Mylan, Biogen, Sanofi-Genzyme, and Merck. Alex Rovira serves on scientific advisory boards for Novartis, Sanofi-Genzyme, Icometrix, Synthetic MR, Bayer, Merck, Biogen, and OLEA Medical and has received speaker honoraria from Bayer, Sanofi-Genzyme, Bracco, Merck-Serono, Teva Pharmaceutical Industries Ltd, Novartis, Roche, and Biogen. Georgina Arrambide has received compensation for consulting services or participation in advisory boards from Sanofi, Merck, and Roche; research support from Novartis; travel expenses for scientific meetings from Novartis and Roche; and speaking honoraria from Stendhal, Sanofi, and Merck. Susana Otero-Romero has received speaking honoraria and consulting fees from Genzyme, Biogen-Idec, Novartis, and MSD and research support from Novartis. Jordi Río has engaged in consulting and/or participated as speaker/ chair in events organized by Merck, Novartis, Sanofi, Roche, Biogen, and Excemed. Manuel Comabella has received compensation for consulting services and speaking honoraria from Bayer Schering Pharma, Merk Serono, Biogen-Idec, Teva Pharmaceuticals, Sanofi-Aventis, Genzyme, and Novartis. Breogan Rodríguez-Acevedo has received honoraria for consulting services from Wellspect. Jaume Sastre-Garriga has engaged in consulting and/or participated as speaker/ chair in events organized by Merck, Novartis, Celgene, Sanofi, Biogen, and Excemed. Xavier Montalban has received speaking honoraria and travel expenses for participation in scientific meetings and has been a steering committee member of clinical trials or participated in advisory boards of clinical trials in the past years with Actelion, Bayer, Biogen, Celgene, Genzyme, Merck, Novartis, Roche, SanofiGenzyme, Teva Pharmaceutical, Excemed, MSIF, and NMSS. Mar Tintoré has received compensation for consulting services and speaking honoraria from Almirall, Bayer Schering Pharma, Biogen-Idec, Genzyme, Merck-Serono, Novartis, Roche, Sanofi-Aventis. and Teva Pharmaceuticals. M. Tintoré is coeditor of Multiple Sclerosis Journal-ETC. Carlos Nos, Joaquin Castilló, Ingrid Galan, Sergio Cabello, Dulce Moncho, Kimia Rahnama, Vanessa Thonon, Ana Zabalza, Luciana Midaglia, and Cristina Auger report no disclosures. Go to Neurology.org/ $\mathrm{N}$ for full disclosures.

\section{Publication History}

Received by Neurology January 15, 2020. Accepted in final form September 1, 2020.

\section{Appendix Authors}

\begin{tabular}{|c|c|c|}
\hline Name & Location & Contribution \\
\hline $\begin{array}{l}\text { Angela Vidal- } \\
\text { Jordana, MD, } \\
\text { PhD }\end{array}$ & $\begin{array}{l}\text { Hospital Universitario } \\
\text { Vall d'Hebron, } \\
\text { Barcelona, Spain }\end{array}$ & $\begin{array}{l}\text { Major role in the acquisition of } \\
\text { data; designed and } \\
\text { conceptualized study; } \\
\text { analyzed the data; performed } \\
\text { statistical analysis; drafted and } \\
\text { revised the manuscript for } \\
\text { intellectual content }\end{array}$ \\
\hline
\end{tabular}

\begin{tabular}{lll}
\hline $\begin{array}{l}\text { Alex Rovira, } \\
\text { MD }\end{array}$ & $\begin{array}{l}\text { Hospital Universitario } \\
\text { Vall d'Hebron, } \\
\text { Barcelona, Spain }\end{array}$ & $\begin{array}{l}\text { Major role in the acquisition } \\
\text { data; interpreted the data; } \\
\text { revised the manuscript for } \\
\text { intellectual content }\end{array}$ \\
\hline $\begin{array}{l}\text { Georgina } \\
\text { Arrambide, } \\
\text { MD, PhD }\end{array}$ & $\begin{array}{l}\text { Hospital Universitario } \\
\text { Vall d'Hebron, }\end{array}$ & $\begin{array}{l}\text { Major role in the acquisition } \\
\text { of data; interpreted } \\
\text { the data; revised the } \\
\text { manuscript for } \\
\text { intellectual } \\
\text { content }\end{array}$ \\
\hline
\end{tabular}

\begin{tabular}{|c|c|c|}
\hline $\begin{array}{l}\text { Susana } \\
\text { Otero- } \\
\text { Romero, MD, } \\
\text { PhD }\end{array}$ & $\begin{array}{l}\text { Hospital Universitario } \\
\text { Vall d'Hebron, } \\
\text { Barcelona, Spain }\end{array}$ & $\begin{array}{l}\text { Interpreted the data; revised } \\
\text { the manuscript for intellectual } \\
\text { content }\end{array}$ \\
\hline $\begin{array}{l}\text { Jordi Rio, MD, } \\
\text { PhD }\end{array}$ & $\begin{array}{l}\text { Hospital Universitario } \\
\text { Vall d'Hebron, } \\
\text { Barcelona, Spain }\end{array}$ & $\begin{array}{l}\text { Major role in the acquisition of } \\
\text { data; revised the manuscript } \\
\text { for intellectual content }\end{array}$ \\
\hline $\begin{array}{l}\text { Manuel } \\
\text { Comabella, } \\
\text { MD, PhD }\end{array}$ & $\begin{array}{l}\text { Hospital Universitario } \\
\text { Vall d'Hebron, } \\
\text { Barcelona, Spain }\end{array}$ & $\begin{array}{l}\text { Major role in the acquisition of } \\
\text { data; revised the manuscript } \\
\text { for intellectual content }\end{array}$ \\
\hline $\begin{array}{l}\text { Carlos Nos, } \\
\text { MD }\end{array}$ & $\begin{array}{l}\text { Hospital Universitario } \\
\text { Vall d'Hebron, } \\
\text { Barcelona, Spain }\end{array}$ & $\begin{array}{l}\text { Major role in the acquisition of } \\
\text { data }\end{array}$ \\
\hline $\begin{array}{l}\text { Joaquin } \\
\text { Castilló, MD, } \\
\text { PhD }\end{array}$ & $\begin{array}{l}\text { Hospital Universitario } \\
\text { Vall d'Hebron, } \\
\text { Barcelona, Spain }\end{array}$ & $\begin{array}{l}\text { Major role in the acquisition of } \\
\text { data }\end{array}$ \\
\hline $\begin{array}{l}\text { Ingrid Galan, } \\
\text { MD }\end{array}$ & $\begin{array}{l}\text { Hospital Universitario } \\
\text { Vall d'Hebron, } \\
\text { Barcelona, Spain }\end{array}$ & $\begin{array}{l}\text { Major role in the acquisition of } \\
\text { data }\end{array}$ \\
\hline $\begin{array}{l}\text { Sergio } \\
\text { Cabello }\end{array}$ & $\begin{array}{l}\text { Hospital Universitario } \\
\text { Vall d'Hebron, } \\
\text { Barcelona, Spain }\end{array}$ & $\begin{array}{l}\text { Major role in the acquisition of } \\
\text { data }\end{array}$ \\
\hline $\begin{array}{l}\text { Dulce } \\
\text { Moncho, MD }\end{array}$ & $\begin{array}{l}\text { Hospital Universitario } \\
\text { Vall d'Hebron, } \\
\text { Barcelona, Spain }\end{array}$ & $\begin{array}{l}\text { Major role in the acquisition of } \\
\text { data }\end{array}$ \\
\hline $\begin{array}{l}\text { Kimia } \\
\text { Rahnama, } \\
\text { MD }\end{array}$ & $\begin{array}{l}\text { Hospital Universitario } \\
\text { Vall d'Hebron, } \\
\text { Barcelona, Spain }\end{array}$ & $\begin{array}{l}\text { Major role in the acquisition of } \\
\text { data }\end{array}$ \\
\hline $\begin{array}{l}\text { Vanessa } \\
\text { Thonon, MD }\end{array}$ & $\begin{array}{l}\text { Hospital Universitario } \\
\text { Vall d'Hebron, } \\
\text { Barcelona, Spain }\end{array}$ & $\begin{array}{l}\text { Major role in the acquisition of } \\
\text { data }\end{array}$ \\
\hline $\begin{array}{l}\text { Breogan } \\
\text { Rodriguez- } \\
\text { Acevedo, MD }\end{array}$ & $\begin{array}{l}\text { Hospital Universitario } \\
\text { Vall d'Hebron, } \\
\text { Barcelona, Spain }\end{array}$ & $\begin{array}{l}\text { Major role in the acquisition of } \\
\text { data }\end{array}$ \\
\hline $\begin{array}{l}\text { Ana Zabalza, } \\
\text { MD }\end{array}$ & $\begin{array}{l}\text { Hospital Universitario } \\
\text { Vall d'Hebron, } \\
\text { Barcelona, Spain }\end{array}$ & $\begin{array}{l}\text { Major role in the acquisition of } \\
\text { data }\end{array}$ \\
\hline $\begin{array}{l}\text { Luciana } \\
\text { Midaglia, MD }\end{array}$ & $\begin{array}{l}\text { Hospital Universitario } \\
\text { Vall d'Hebron, } \\
\text { Barcelona, Spain }\end{array}$ & $\begin{array}{l}\text { Major role in the acquisition of } \\
\text { data }\end{array}$ \\
\hline $\begin{array}{l}\text { Cristina } \\
\text { Auger, MD }\end{array}$ & $\begin{array}{l}\text { Hospital Universitario } \\
\text { Vall d'Hebron, } \\
\text { Barcelona, Spain }\end{array}$ & $\begin{array}{l}\text { Major role in the acquisition of } \\
\text { data; revised the manuscript } \\
\text { for intellectual content }\end{array}$ \\
\hline
\end{tabular}


Appendix (continued)

\begin{tabular}{lll}
\hline Name & Location & Contribution \\
\hline $\begin{array}{l}\text { Jaume } \\
\text { Sastre- } \\
\text { Garriga, MD, } \\
\text { PhD }\end{array}$ & $\begin{array}{l}\text { Hospital Universitario } \\
\text { Vall d'Hebron, } \\
\text { Barcelona, Spain }\end{array}$ & $\begin{array}{l}\text { Major role in the acquisition of } \\
\text { data; revised the manuscript } \\
\text { for intellectual content }\end{array}$ \\
$\begin{array}{l}\text { Xavier } \\
\text { Montalban, } \\
\text { MD, PhD }\end{array}$ & $\begin{array}{l}\text { Vospital Universitario d'Hebron, } \\
\text { Barcelona, Spain }\end{array}$ & $\begin{array}{l}\text { Interpreted the data, revised } \\
\text { the manuscript for intellectual } \\
\text { content }\end{array}$ \\
\hline $\begin{array}{l}\text { Mar Tintoré, } \\
\text { MD, PhD }\end{array}$ & $\begin{array}{l}\text { Hospital Universitario } \\
\text { Vall d'Hebron, } \\
\text { Barcelona, Spain }\end{array}$ & $\begin{array}{l}\text { Designed and conceptualized } \\
\text { study, interpreted the data, } \\
\text { revised the manuscript for } \\
\text { intellectual content }\end{array}$ \\
& & \\
\hline
\end{tabular}

\section{References}

1. McDonald WI, Compston A, Edan G, et al. Recommended diagnostic criteria for multiple sclerosis: guidelines from the International Panel on the Diagnosis of Multiple Sclerosis. Ann Neurol 2001;50:121-127.

2. Polman CH, Reingold SC, Banwell B, et al. Diagnostic criteria for multiple sclerosis: 2010 revisions to the McDonald criteria. Ann Neurol 2011;69:292-302.

3. Thompson AJ, Banwell BL, Barkhof F, et al. Diagnosis of multiple sclerosis: 2017 revisions of the McDonald criteria. Lancet Neurol 2018;17:162-173.

4. Arrambide G, Tintore M, Espejo C, et al. The value of oligoclonal bands in the multiple sclerosis diagnostic criteria. Brain 2018;141:1075-1084.

5. Toosy AT, Mason DF, Miller DH. Optic neuritis. Lancet Neurol 2014;13:83-99.

6. Tintore M, Rovira A, Río J, et al. Defining high, medium and low impact prognostic factors for developing multiple sclerosis. Brain 2015;138:1863-1874.

7. Filippi M, Rocca MA, Ciccarelli O, et al. MRI criteria for the diagnosis of multiple sclerosis: MAGNIMS consensus guidelines. Lancet Neurol 2016;15:292-303.

8. Brownlee WJ, Miszkiel KA, Tur C, Barkhof F, Miller DH, Ciccarelli O. Inclusion of optic nerve involvement in dissemination in space criteria for multiple sclerosis. Neurology 2018;91:e1130-e1134.

9. Filippi M, Preziosa P, Meani A, et al. Prediction of a multiple sclerosis diagnosis in patients with clinically isolated syndrome using the 2016 MAGNIMS and 2010 McDonald criteria: a retrospective study. Lancet Neurol 2018;17:133-142.

10. Knier B, Berthele A, Buck D, et al. Optical coherence tomography indicates disease activity prior to clinical onset of central nervous system demyelination. Mult Scler J 2015;22:893-900.

11. Zimmermann HG, Knier B, Oberwahrenbrock $\mathrm{T}$, et al. Association of retinal ganglion cell layer thickness with future disease activity in patients with clinically isolated syndrome. JAMA Neurol 2018;75:1071-1079.

12. London F, Zéphir H, Drumez E, et al. Optical coherence tomography: a window to the optic nerve in clinically isolated syndrome. Brain 2019;142:903-915.

13. Oberwahrenbrock $\mathrm{T}$, Ringelstein $\mathrm{M}$, Jentschke $\mathrm{S}$, et al. Retinal ganglion cell and inner plexiform layer thinning in clinically isolated syndrome. Mult Scler J 2013;19:1887-1895.

14. London F, Zéphir H, Hadhoum N, et al. Optic nerve double inversion recovery hypersignal in patients with clinically isolated syndrome is associated with asymptomatic gadolinium-enhanced lesion. Mult Scler J 2019;25:1888-1895.
15. Arrambide G, Rovira A, Sastre-Garriga J, et al. Spinal cord lesions: a modest contributor to diagnosis in clinically isolated syndromes but a relevant prognostic factor. Mult Scler J 2018;24:301-312.

16. Odom JV, Bach M, Brigell M, et al. International Society for Clinical Electrophysiology of Vision. ISCEV standard for clinical visual evoked potentials: (2016 update). Doc Ophthalmol 2016;133:1-9.

17. Poser CM, Paty DW, Scheinberg L, et al. New diagnostic criteria for multiple sclerosis: guidelines for research protocols. Ann Neurol 1983;13:227-231.

18. Leocani L, Guerrieri S, Comi G. Visual evoked potentials as a biomarker in multiple sclerosis and associated optic neuritis. J Neuroophthalmol 2018;38: 350-357.

19. Tintore M, Otero-Romero S, Río J, et al. Contribution of the symptomatic lesion in establishing MS diagnosis and prognosis. Neurology 2016;87:1368-1374.

20. Brownlee WJ, Swanton JK, Miszkiel KA, Miller DH, Ciccarelli O. Should the symptomatic region be included in dissemination in space in MRI criteria for MS? Neurology 2016;87:680-683.

21. Gundogan FC, Tas A, Altun S, Oz O, Erdem U, Sobaci G. Color vision versus pattern visual evoked potentials in the assessment of subclinical optic pathway involvement in multiple sclerosis. Indian J Ophthalmol 2013;61:100-103.

22. Sisto D, Trojano M, Vetrugno M, Trabucco T, Iliceto G, Sborgia C. Subclinical visual involvement in multiple sclerosis: a study by MRI, VEPs, frequency-doubling perimetry, standard perimetry, and contrast sensitivity. Investig Opthalmology Vis Sci 2005;46:1264

23. Yuksel B, Dogan B, Koctekin B, et al. Color vision testing versus pattern visual evoked potentials and optical coherence tomography parameters in subclinical optic nerve involvement in multiple sclerosis. J Clin Neurosci 2019;61:48-53.

24. Stunkel L, Kung NH, Wilson B, McClelland CM, Van Stavern GP. Incidence and causes of overdiagnosis of optic neuritis. JAMA Ophthalmol 2018;136:76-81.

25. Paty DW, Oger JJ, Kastrukoff LF, et al. MRI in the diagnosis of MS: a prospective study with comparison of clinical evaluation, evoked potentials, oligoclonal banding, and CT. Neurology 1988;38:180-185.

26. Lee KH, Hashimoto SA, Hooge JP, et al. Magnetic resonance imaging of the head in the diagnosis of multiple sclerosis: a prospective 2-year follow-up with comparison of clinical evaluation, evoked potentials, oligoclonal banding, and CT. Neurology 1991;41:657-660.

27. Filippini G, Comi GC, Cosi V, et al. Sensitivities and predictive values of paraclinical tests for diagnosing multiple sclerosis. J Neurol 1994;241:132-137.

28. Martinelli V, Dalla Costa G, Messina MJ, et al. Multiple biomarkers improve the prediction of multiple sclerosis in clinically isolated syndromes. Acta Neurol Scand 2017;136:454-461.

29. Gabelić T, Radmilović M, Posavec V, et al. Differences in oligoclonal bands and visual evoked potentials in patients with radiologically and clinically isolated syndrome. Acta Neurol Belg 2013;113:13-17.

30. Walsh P. The clinical role of evoked potentials. J Neurol Neurosurg Psychiatry 2005 76:ii16-ii22.

31. Barton JL, Garber JY, Klistorner A, Barnett MH. The electrophysiological as sessment of visual function in multiple sclerosis. Clin Neurophysiol Pract 2019; 4:90-96.

32. Galetta SL, Balcer LJ. The optic nerve should be included as one of the typical CNS regions for establishing dissemination in space when diagnosing MS: yes. Mult Scler J 2018;24:121-122.

33. Tintore $\mathrm{M}$, Montalban X. The optic nerve should be included as one of the typical CNS regions for establishing dissemination in space when diagnosing MS: no. Mult Scler J 2018;24:123-125.

34. Barkhof F. The optic nerve should be included as one of the typical CNS regions for establishing dissemination in space when diagnosing MS: commentary. Mult Scler J 2018;24:125-126. 


\section{Neurology}

\section{Optic Nerve Topography in Multiple Sclerosis Diagnosis: The Utility of Visual Evoked Potentials}

Angela Vidal-Jordana, Alex Rovira, Georgina Arrambide, et al. Neurology 2021;96;e482-e490 Published Online before print December 16, 2020

DOI 10.1212/WNL.0000000000011339

This information is current as of December 16, 2020

\section{Updated Information \&} Services

References

Citations

Subspecialty Collections

Permissions \& Licensing

\section{Reprints}

including high resolution figures, can be found at: http://n.neurology.org/content/96/4/e482.full

This article cites 34 articles, 5 of which you can access for free at: http://n.neurology.org/content/96/4/e482.full\#ref-list-1

This article has been cited by 2 HighWire-hosted articles: http://n.neurology.org/content/96/4/e482.full\#\#otherarticles

This article, along with others on similar topics, appears in the following collection(s):

Autoimmune diseases

http://n.neurology.org/cgi/collection/autoimmune_diseases

Evoked Potentials/Visual

http://n.neurology.org/cgi/collection/evoked_potentials-visual

Multiple sclerosis

http://n.neurology.org/cgi/collection/multiple_sclerosis Optic neuritis; see Neuro-ophthalmology/Optic Nerve http://n.neurology.org/cgi/collection/optic_neuritis

Information about reproducing this article in parts (figures,tables) or in its entirety can be found online at:

http://www.neurology.org/about/about_the_journal\#permissions

Information about ordering reprints can be found online:

http://n.neurology.org/subscribers/advertise

Neurology ${ }^{\circledR}$ is the official journal of the American Academy of Neurology. Published continuously since 1951, it is now a weekly with 48 issues per year. Copyright Copyright @ 2020 The Author(s). Published by Wolters Kluwer Health, Inc. on behalf of the American Academy of Neurology.. All rights reserved. Print ISSN: 0028-3878. Online ISSN: 1526-632X.

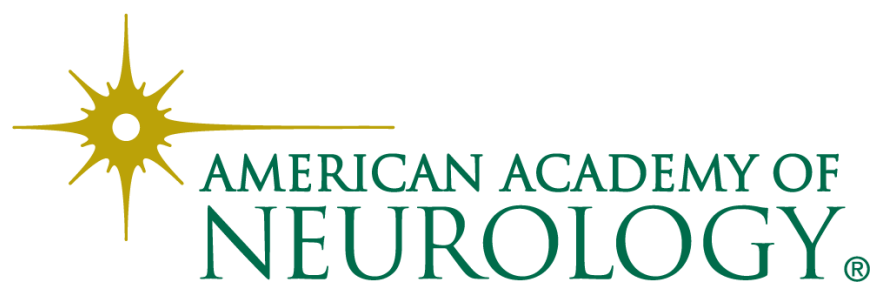

